\title{
SELECTIVE CHEMICAL ETCHING FOR STUDYING THE FRONT SIDE CONTACT IN THICK FILM SCREEN PRINTED CRYSTALLINE P-TYPE SILICON SOLAR CELLS
}

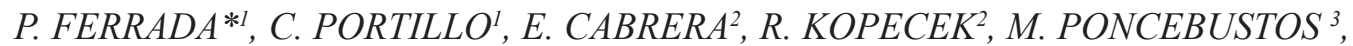 \\ M. J. KOGAN ${ }^{3}$, V. DEL CAMPO', AND E. FUENTEALBA ${ }^{1}$ \\ ${ }^{1}$ Centro de Desarrollo Energético Antofagasta (CDEA), Universidad de Antofagasta, Av. Angamos 601,1270300 Antofagasta, Chile \\ ${ }^{2}$ International Solar Energy Research Center Konstanz (ISC-Konstanz), Rudolf-Diesel-Str. 15, D-78467 Konstanz, Germany \\ ${ }^{3}$ Departamento de Química Farmacológica y Toxicológica, and advance center for Chronic diseases (ACCDiS), Universidad de Chile, \\ Santos Dumont 964, Santiago, Chile \\ ${ }^{4}$ Departamento de Física, Universidad Técnica Federico Santa María, Av. España 1680, Valparaíso, Chile
}

\begin{abstract}
Crystalline silicon solar cells are currently the leading technology in the photovoltaic market with no great expectable change in the shares. The scientific community works on the further development and improvements of state-of-the-art as well as new solar cell materials. This paper reports on a chemical methodology for selective etching to study the metallization step in monocrystalline silicon solar cells. The object of study is a complete processed silicon solar cell which was cleaved via laser beam on the back side and broken per hand to obtain stripes of the size $15.6 \times 1 \mathrm{~cm}^{2}$. In the following a sequence of etching chemical solutions to selectively remove the components of the front side silver contact was applied. Scanning electron microscopy was used to investigate contact interface after each etching step. The silver finger, the glass and the silver crystallites grown in silicon could be removed. It came out that the silver crystallites preferably grow at the pyramid tips and edges of the textured wafer. A characterization with Energy Dispersive X-Ray Spectrometry was performed to quantify the components of the silver contact after each chemical etching step. While the weight percentage of silver reduced by more than $90 \%$ after an aqua regia treatment, it increased by $13 \%$ after hydrofluoric acid. Silver was practically eliminated after a second aqua regia bath. Similarly, the content of glass was also determined. The approach serves for interface investigations in semiconductor technology where screen printing approaches are used for the metallization.
\end{abstract}

Keywords: Selective Etching, Crystalline Solar Cells, Screen Printing, Thick Film Silver Paste, Scanning Electron Microscopy, Energy Dispersive X-Ray Spectrometry.

\section{INTRODUCTION}

The Fondap project Solar Energy Research Center (SERC Chile), as a consortium of 6 Chilean universities including the Universidad de Chile (UCH), the Universidad de Antofagasta (UA), and the Universidad Técnica Federico Santa María (URFSM) among others, has the aim of developing the applied and basic research of Solar Energy in Chile. This research includes the field of materials sciences for photovoltaics, especially for industrial solar cells. Likewise, the Centro de Desarrollo Energético Antofagasta (CDEA) of the Universidad de Antofagasta has the purpose of developing solar energy research in the Antofagasta region, northern Chile. Hence, this paper focuses on the study of one of the most critical steps within the fabrication, the metallization. In the future, a fabrication laboratory may be implemented in Chile in order to produce industrial photovoltaic cells. To accomplish this goal, SERC and CDEA perform collaborative research with the International Solar Energy Research Center (ISC) Konstanz (Germany).

Photovoltaics (PV) has rapidly grown to become an important source of energy and economic activity. By 2013 close to $90 \%$ of the PV technology was based on bulk Si-wafer, consisting of monocrystalline $\mathrm{Si}$ (mono $\mathrm{Si}$ ) and multicrystalline $\mathrm{Si}(\mathrm{mc}-\mathrm{Si}){ }^{1}$. Notwithstanding that Silicon photovoltaics (SiPV) can be seen as a mature technology, the scientific community works on the further improvement in several areas such as the crystallization, producing thinner wafers, optimizing solar cell process, switching substrate from p-type to n-type doped silicon, using new metallization materials, modifying solar cell structures and reducing hazardous elements, among others ${ }^{2}$.

The metallization is decisive for the sustainability of SiPV due to the high cost of silver used for the front side contact on standard p-type Si solar cells. Thus, reducing its amount is desired. With this regard, optimizing the silver metallization has been a successful way to produce a contact in silicon alternatively to its replacement ${ }^{3}$.

The aim of this work is to demonstrate a methodology of selective chemical etching to investigate the front side contact after removing the sintered silver and underlying components. Solar cell samples can be systematically been prepared to find the best chemistry of the silver paste used for producing the electrical contact in industrial solar cells and the best set of parameters for fabrication. A description of the silicon solar cell is given in the appendix.

\section{METALLIZATION OF C-SI SOLAR CELLS}

The metallization of c-Si solar cells is performed at the final stages within the fabrication, and represents a critical step due to the number of processes and reactions which take place in a short period of time (see firing step in subsection 2.3.). Before creating electrical contacts in a solar cell, a sequence of several steps are required ${ }^{4}$, which can be seen in the appendix.

\subsection{Screen printing}

The most used metallization technology in the industry is screen printing. A screen consists of a mesh made of stainless steel and coated by an emulsion. The technology is based on the use of thick metal pastes deposited by applying a squeegee force which allows that the pastes flow through the openings of the screen. Silver paste (containing Ag particles) is used to establish a contact onto n-type silicon, and aluminum (containing Al particles) to contact p-type silicon material. Both pastes contains further components to ensure both: a necessary low viscosity to print over the wafer surface and a higher viscosity after the printing step (see section 2.2). While silver paste is deposited onto $\mathrm{SiNx}^{5}$ and therefore designed to etch this layer, aluminum paste is just utilized to support the contact formation and not to etch $\mathrm{SiNx}^{6}$.

Immediately after depositing silver or aluminum paste, a drying step follows at temperatures between $80^{\circ} \mathrm{C}$ and $200^{\circ} \mathrm{C}$ to remove the solvent (see the detailed firing cycle in section 2.4). Since in a p-type based silicon solar cell process, Ag fingers and busbars are used in the front side, they must cause the minimal possible shadowing while ensuring a good contact, and avoiding the introduction of metal impurities deep into the substrate due to recombination losses. In addition, aluminum cannot be soldered to construct a module, therefore solder pads are screen printed on the rear side with a silver-aluminum ( $\mathrm{AgAl})$ paste, exactly in the equivalent position as the busbars of the front side. This step is generally performed after printing silver on the front side and before printing aluminum on the rear. Fig. 1 illustrate the finished front side Ag contact.

2.2. The silver paste

The silver paste consists of the following ingredients: Ag particles, glass frit, solvents, and binders. Ag particles can have different shape and size distribution with concentrations in the range $70-95 \mathrm{wt} \%$ of the paste system. A frequent used glass, lead-borosilicate glass $\left(\mathrm{PbO}_{\mathrm{B}_{2}} \mathrm{O}_{3}: \mathrm{SiO}_{2}\right)$, exhibits a concentration close to $5 \mathrm{wt} \%$ of the paste system. The glass etches the $\mathrm{SiNx}$ layer and reduces the melting point of silver during a high temperature process (see section 2.3.). The glass allows for achieving a mechanical adhesion to 
the substrate after firing. Solvents and binders are required to adjust the paste rheology. They are based on ethyl cellulose, in combination with terpineol ${ }^{7}$ and are chosen in such a way that they are burn off during firing without leaving residues back.

Typically, glasses of the type $\mathrm{PbO}: \mathrm{B}_{2} \mathrm{O}_{3}: \mathrm{SiO}_{2}$ are used for screen printed silicon solar cells. Alternatively, $\mathrm{Bi}_{2} \mathrm{O}_{3}, \mathrm{ZnO}$, etc can replace $\mathrm{PbO}$ due to toxicity reasons ${ }^{8,9}$.

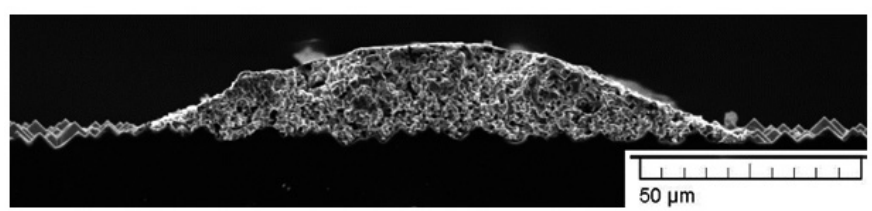
cell.

Fig. 1. SEM image of the front Ag contact of a complete processed solar

\subsection{Firing}

After screen printing and drying, the wafers flow inside a firing infrared (IR) belt furnace. This furnace is circa $7 \mathrm{~m}$ long with 6 heating zones to achieve a temperature-time (T-t) profile as shown in Fig. 2. The parameters which are normally adjusted are the peak firing temperature $\left(\mathrm{T}_{\text {peak }}\right)$ of zones 5 and 6 , and the belt speed $\left(\mathrm{v}_{\text {bell }}\right)$

During the firing step, components of the paste and silicon interact: organics burn out, the glass melts and locally etches the SiNx layer followed by the dissolution of silver particles and sintering. The sintered Ag particles result in thick Ag fingers and busbars on the front side of the solar cell ${ }^{10}$ In the regions where SiNx is completely removed, the melted glass reaches n-type silicon, anisotropically etching and dissolving silicon. When the system is cooling down the glass establishes a mechanical contact with silicon, the dissolved silicon regrows epitaxially and silver recrystallizes at the glass/ silicon interface in the form of $\mathrm{Ag}$ crystallites (Fig. 3) ${ }^{11}$.

During the firing step, further processes take place. Hydrogen diffuses from the H-rich SiNx layer into bulk silicon. Hydrogen is present in the precursors used for the PECVD ${ }^{4}$. An aluminum alloyed back surface field (BSF) is created ${ }^{12}$ (the BSF is a diffused layer with the same doping type as the basis, establishing a high-low junction $\mathrm{p}^{+} \mathrm{p}$ ). BSF reduces recombination losses to some extent at the rear side of the solar cell. In addition, the aluminum back contact to the BSF and the contact pads are formed.

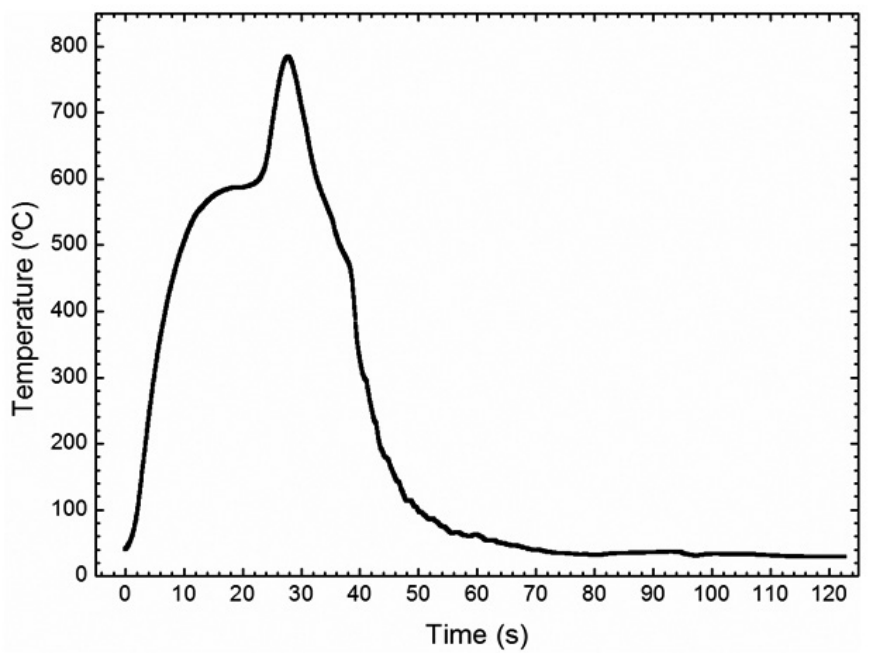

Fig. 2. Typical T-t firing profile determined with a temperature sensor and a datalogger in which the actual temperature of the cell's surface was measured

\subsection{Detailed firing cycle}

In the following, a summarized description of the firing step is given ${ }^{14,16}$.

(1) For $T<550{ }^{\circ} \mathrm{C}$ : The organic binders and solvents are burned off. The viscosity of the glass frit starts to decrease. The sintering of silver particles begins.

(2) For $T>550{ }^{\circ} \mathrm{C}$ : The fluid glass dissolves the silver below its melting point and wets the $\mathrm{SiN} x$ layer. The $\mathrm{SiNx}$ is etched by a redox reaction with the $\mathrm{PbO}$ glass: $\mathrm{PbO}$ is partially reduced to $\mathrm{Pb}$ and $\mathrm{N}_{2}$ is simultaneously burned off. $\mathrm{Si}$ is oxidized and incorporated as $\mathrm{SiO}_{2}$ in the glass layer.
(3) For $700{ }^{\circ} \mathrm{C}<T<800{ }^{\circ} \mathrm{C}, \mathrm{PbO}$ reacts with $\mathrm{Si}$ resulting in $\mathrm{Pb}$ and $\mathrm{SiO}_{2}$. Thus, more $\mathrm{SiO}_{2}$ is dissolved in the glass frit whereas liquid $\mathrm{Pb}$ starts to accumulate underneath the silver bulk. More silver is dissolved in the liquid $\mathrm{Pb}$ and accumulates near the Si interface. Silver starts to crystallize epitaxially into the $\mathrm{Si}$ with the assumption that the growth is either from silver saturated glass or via liquid lead phase.

(4) After $T_{\text {peak }}$ has been reached, the rapid cooling down begins. Inverted pyramids composed mostly of silver are randomly created along $\mathrm{Si}$ planes whereas $\mathrm{Pb}$ is solidified underneath the silver bulk increasing the metal precipitates in the matrix glass. Few SiNx areas still remain and an inhomogeneous glass layer is distributed on the Si surface.

\subsection{Model on the current transport}

A complete processed solar cell with screen printed Ag contact is made up of the following components: Ag silver bulk produced after the sintering of $\mathrm{Ag}$ particles, the glass layer, $\mathrm{Ag}$ crystallites grown into the Si n-type emitter in direct contact with the Ag bulk, Ag crystallites isolated by a thin glass layer, Ag crystallites isolated by a thick glass layer and metal precipitates. Fig. 3 (a) shows the model of the current transport according to ${ }^{15}$ and Fig. 3 (b) is an image of a case where a $\mathrm{Ag}$ crystallite is completely isolated from Ag bulk by a glass layer.

(a)

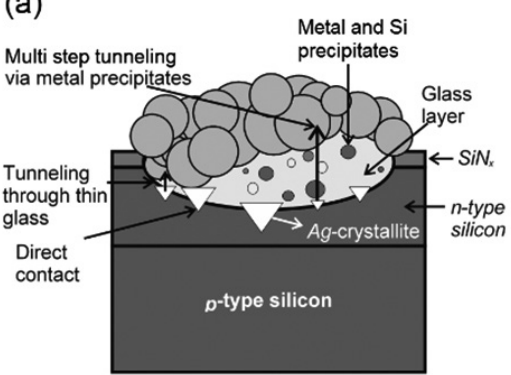

(b)

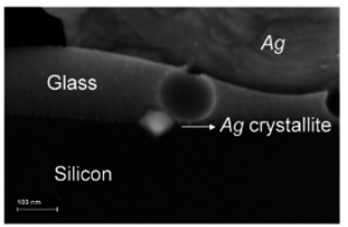

Fig. 3(a): Possible current transport mechanisms in a silver contact. Fig. 3(b): TEM image of a silver crystallite isolated from the Ag bulk.

Possible paths depicted in Fig. 3(a) for the current transport between $\mathrm{Ag}$ bulk and silicon are:

- $\quad$ Direct current flow through Ag crystallites in direct contact to the silver bulk ${ }^{15}$

- Current flow through the Ag crystallites separated by a thin glass layer from the silver finger bulk $16,17,18,19,20$.

- Current flow through the Ag crystallites separated from the silver finger by a glass layer and tunneling effect due to metal precipitates in the glass ${ }^{16,19}$.

- The current transport occurs through a multistep tunneling supported by nano-Ag colloids in the thin glass layer close to the silicon ${ }^{21}$.

\section{METHODOLOGY}

\subsection{Studying the front side silver contact}

Several characterization approaches can be used to study the resulting contact and the contact formation: electrical measurements such as the transfer length method (TLM) with a 4-Point Probe device to determine the contact and specific contact resistance of a metallized silver contact on silicon. The same device allows for measuring the line resistance of the contact. Spatially resolved imaging based such as electroluminescence (EL) and photoluminescence (PL) are used both to generate a map of the recombination and the resistive losses in a solar cell ${ }^{22,23,24}$. An illumination level dependent open circuit voltage (SunsVoc) device can be used to measure leakage currents (also called shunting) ${ }^{25}$. The resulting silver finger width and height can be determined with a confocal laser scanning microscope (LSM). The solar cell current-voltage (IV) characteristics were determined with a Sun Simulator. These methods were used in this work to characterize the finished solar cells. The screen printed contact interface was investigated with a FEI Inspect F-50 scanning electron microscope with Field Emission Gun (FE-SEM) at the U. de Chile.

In the following, the selective chemical etching method, applied to the structure depicted in section 2.6., is described.

\subsection{Samples}

Crystalline silicon solar cells were processed in a standard run, as described in subsection 2.1., at the International Solar Energy Research Center Konstanz 
(ISC Konstanz), Germany. The starting material was p-type (100) oriented mono crystalline silicon wafers of $15.6 \times 15.6 \mathrm{~cm}^{2}$ area, $3-6 \Omega \mathrm{cm}$ base resistivity and $180 \mu \mathrm{m}$ thickness. The screen for the front side had a $2.2 \mathrm{~mm}$ finger distance and $50 \mu \mathrm{m}$ finger opening. A commercial silver paste, from which a solar cell efficiency above $18 \%$ is expected, was used. For the firing step, optimum parameters were previously found and set for the current experiment at ISC. For LSM and SEM characterization, solar cells were cleaved by laser beam on the back side and broken per hand to obtain 9 stripes of size $15.6 \times 1$ $\mathrm{cm}^{2}$ (see Fig. 4a).

\subsection{Selective chemical etching approach}

The selective chemical etching was performed at the chemistry laboratory of the Universidad de Antofagasta with the following solutions (quality for analysis).

- Aqua regia (AR) consisting of a solution of $\mathrm{HCl}(37 \%)$ and $\mathrm{HNO}_{3}$ $(65 \%)$ in a $3: 1$ proportion to remove silver (Fig. $4 \mathrm{~b}$ and Fig. $4 \mathrm{c}$ ). As AR is a strong oxidizing agent, it will not etch the glass ${ }^{26}$.

- $\quad$ Hydrofluoric acid, HF (5\%) to remove the glass (Fig. 4d).

- Deionized water was used between steps before dipping into the subsequent acid (Fig. 4d).

First, 9 stripes were immersed in test tubes filled with circa $40 \mathrm{ml}$ of AR solution for $60 \mathrm{~min}$ (Fig. 4b and Fig. 4c). After DI water dip, 3 of the 9 stripes were dried at $60^{\circ} \mathrm{C}$ and stored.

Second, the next 6 stripes were etched 5 min with HF in plastic beakers and dipped in DI water (Fig. 4d). In the following, 3 of the 6 stripes were dried and stored.

Third, the remaining 3 stripes were immersed again in AR for $60 \mathrm{~min}$ followed by DI water dip. The stripes were dried and stored.

\section{RESULTS AND DISCUSSION}

The results are presented in two subsections. First, quantitative measurements after IV and LSM characterization. Second, SEM and EDX analysis of the contact interface.

\subsection{IV and LSM characterization}

Table 1 summarizes the IV characteristics. The IV values were determined at standard testing conditions or STC $\left(1000 \mathrm{~W} / \mathrm{m}^{2}\right.$ at 1.5 air mass spectrum and cell temperature of $25^{\circ} \mathrm{C}$ ). The silver paste used to metallize the solar cells led an efficiency of $19 \%$. The EL and PL of Fig. 5 show a homogeneous emission, indicating no local losses due to resistive effects. This solar cell (Fig. 5) was used for SEM analysis. Moreover, the Suns Voc characterization gives a pseudo fill factor $(p F F)$ much higher than $F F(83 \%$ versus $78 \%)$ demonstrating no leakage currents through the $\mathrm{p}-\mathrm{n}$ junction (see calculation below). This quantity accounts for the fill factor without the series resistance because the open circuit voltage is determined at varying irradiation intensities without drawing the current from the solar cell. In that way, it gives direct indication whether a solar cell exhibits leakage current or not ${ }^{25}$. Note that the fill factor is defined as $F F=V_{m p p} \cdot \mathrm{J}_{m p p} /\left(V_{o c} \cdot \mathrm{J}_{s c}\right)$. The $V_{m p p}$ and $J_{m p p}$ are respectively the voltage and current at the maximum power point. The $V_{o c}^{m p p}$ is the open circuit voltage and $J_{s c}$ is the short circuit current density.

Table 1: Summary of measurements.

\begin{tabular}{|c|c|}
\hline Measurements & $\begin{array}{c}\text { Average and standard } \\
\text { deviation (15 solar cells) }\end{array}$ \\
\hline Efficiency $(\%)$ & $19.0 \pm 0.1$ \\
\hline Voltage at maximum power point, $V_{m p p}(\mathrm{mV})$ & $538.7 \pm 0.1$ \\
\hline $\begin{array}{c}\text { Current density at maximum power point, } \\
J_{m p p}\left(\mathrm{~mA} / \mathrm{cm}^{2}\right)\end{array}$ & $35.2 \pm 2$ \\
\hline Open circuit voltage, $V_{o c}(\mathrm{mV})$ & $644.8 \pm 0.4$ \\
\hline Short circuit current density, $J_{s c}\left(\mathrm{~mA} / \mathrm{cm}^{2}\right)$ & $37.6 \pm 0.1$ \\
\hline Fill factor, $F F(\%)$ & $78.2 \pm 0.2$ \\
\hline Pseudo fill factor, $p F F(\%)$ & $83.70 \pm 0.04$ \\
\hline
\end{tabular}

In order to calculate a theoretical maximum value of the fill factor, a wellknown expression can be used ${ }^{27}$ :

$$
F F_{m}=\frac{v_{o c}-\ln \left(v_{o c}-0.72\right)}{v_{o c}+1}
$$

The normalized open circuit voltage is given by $v_{o c}=q \cdot V_{o c} /\left(n \cdot k_{B} \cdot T\right)$ where $q$ is the elementary charge, $V_{o c}$ is the measured $V_{o c}$ at STC, $n$ is the ideality factor accounting for recombination, $k_{B}$ is the Boltzmann constant and $T$ temperature. Replacing values of Table $1, p F F=F F \approx 84 \%$ which is higher than $F F=78 \%$.

A LSM image of the analyzed silver fingers is shown in Fig. 5. The finished screen printed silver finger exhibits neither a constant width $(91.7 \pm 2.6 \mu \mathrm{m})$ nor a height $(17.1 \pm 0.4 \mu \mathrm{m})$ due to the inhomogeneous particle distribution and different stages of the firing step described in subsection 2.5. At initial stages, the solvent is evaporated and the organic binder is burned off, which in turn, leads to voids in the structure.
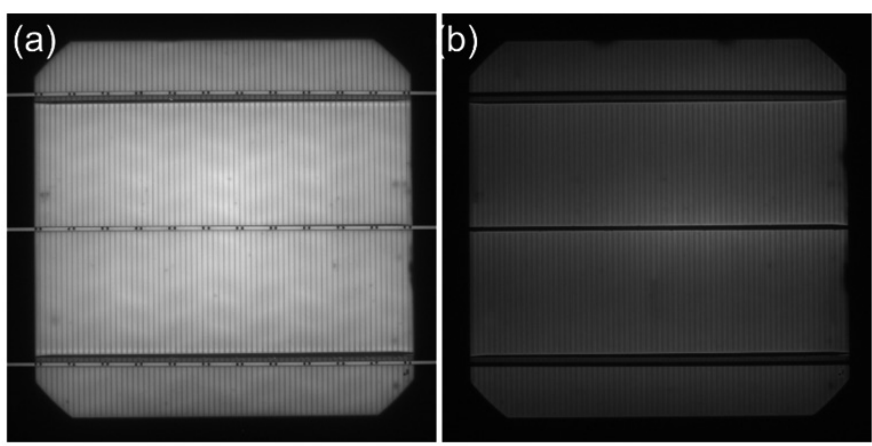

Fig. 5. (a) Photoluminescence. (b) Electroluminescence.

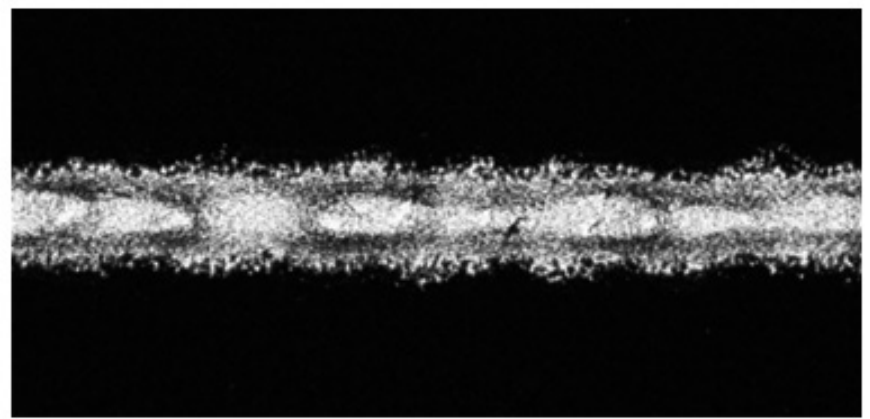

Fig. 6. LSM image of a finished silver finger.

\subsection{SEM analysis of the contact interface}

The SEM images in Fig. 7 correspond to the sample which was treated only with AR, Fig. 8 to the sample which received AR and subsequential HF etch, and Fig. 9 to the sample which was etched first with AR, HF solution and a second AR etch. The letters (a) to (e) at the images correspond to the lowest to the highest maximization used. The red squares, starting with (a) define the scan region for the next image.

The region which was screen printed can be distinguished in Fig. 7a showing also bare silicon out from the metallized region. Fig. 7b and Fig. 7c indicate that the glass layer is distributed over the printed region and seems to not leave pyramid tips free, i.e. it covers the pyramid up to the tips. Fig. $7 \mathrm{~d}$ is a close up of the central pyramid.

Fig. 8a to Fig. 8d expose the silver behind the glass after a first AR and HF etch. Silver crystallites must have grown in silicon. Fig. 8d suggests that silver crystallites grew at the tips of the pyramids and edges, however, they are not easily distinguished. In order to verify this hypothesis, the next etching step can reveal where silver crystallites have grown.

Fig. 9a can hardly reveal the contact places or contact imprints. Closing up in Fig. 9b, silver rests are distinguishable. Fig. 9c and 9d show contact imprints located at the pyramid and edges closed to the tips. These positions are the only places where silver crystallites can have grown supported by the imprint locations. The pattern is repeated for the whole metallized region. Fig. $9 \mathrm{e}$ is a further closed up of a metallized region after the application of the three etching chemical solutions confirming that the only places where silver crystallites have grown are the pyramid tips and edges close to the tip. 

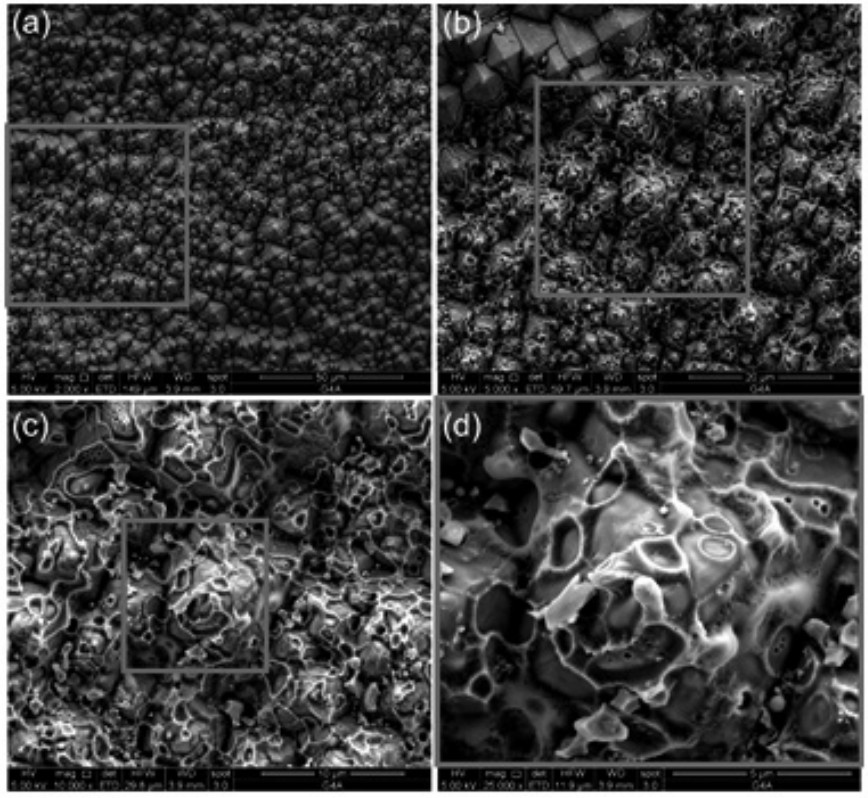

Fig. 7. Glass covering Si pyramids after AR etch.
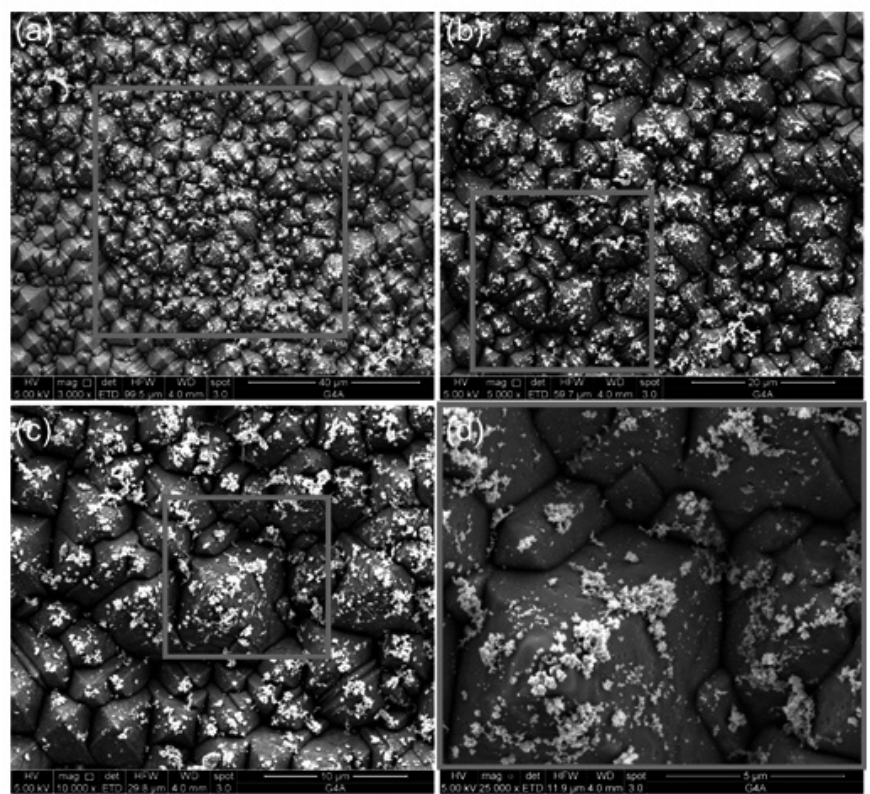

Fig. 8: Ag crystallites after AR and HF etch.

Regarding the size and shape of the contact imprints, they keep a defined geometry (Fig. 9e) which is directly related with the crystal orientation. While squared base inverted pyramids are formed onto a (100) oriented silicon, triangles shapes grow on (111) oriented planes such as the surface of the textured monocrystalline silicon solar cell ${ }^{11,16,18}$. In this concern, an investigation suggested that it is easier to remove an initial atom from the edge of a pyramid than from the center of a (100) surface ${ }^{11}$. Thus, crystallite formation must occur preferably at tips and edges. Another point into discussion is the influence of components of the silver paste during the firing step. New paste generations are designed to produce a contact matrix in which the glass does not cover the pyramid tips completely, i.e. the glass leaves pyramid tips free, or at least, it leads to a thinner glass layer at the top region (Fig. 3a). As a result, silver crystallites in direct contact to the silver bulk are created. In order that this effect takes place and the glass concentrates in the valleys, pyramids needs to have an optimized size ${ }^{28}$. There are other factors which influence the contact formation such as the properties of the silver particles, size and shape of the pyramids and the doping of silicon. In this work, however, the process parameters to control them were not varied. For high solar cell efficiencies, the firing step must be studied and adapted to the silver paste and the mentioned factors in discussion.

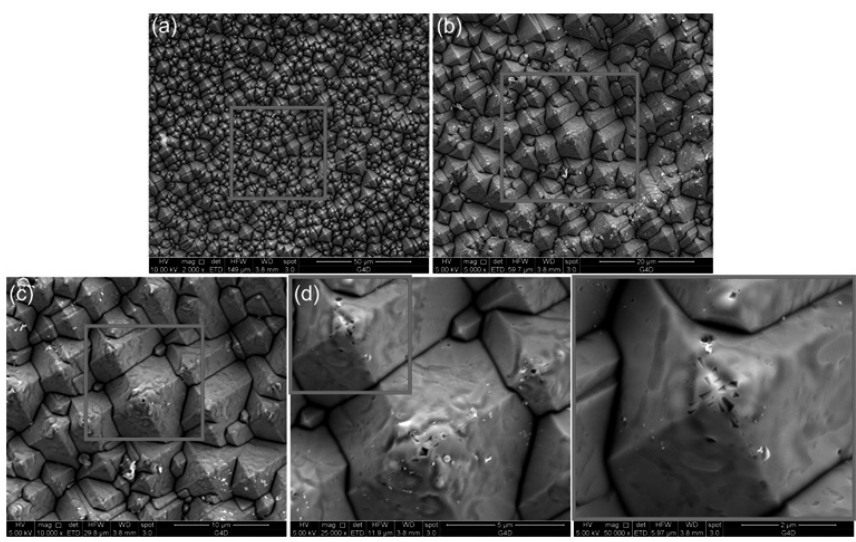

Fig. 9: Contact imprints after AR, HF and AR etch.

In case of the silver particles in the paste, increasing their size can lead to more silver dissolved in the glass, creating larger crystallites, and resulting degradation of $V_{o c}$ and $F F$ values due to leakage current through the junction 30. Regarding the doping of silicon, it has been reported that the size and penetration of silver crystallites is influenced by the phosphorus doping concentration of the n-type silicon ${ }^{11,30}$. For an n-type layer produced by $\mathrm{POCl}_{3}$ diffusion, SiP precipitates are produced by the excess of phosphorus at the surface and may facilitate the nucleation of silver crystallites ${ }^{20}$.

1.3 EDX analysis

Samples for EDX analysis were cleaned under a nitrogen blow before the element quantification. In order to improve statistics, areas of different sizes (from $100 \mu \mathrm{m}^{2}$ to $2500 \mu \mathrm{m}^{2}$ ) were scanned and an average concentration was obtained for each type of sample.

Fig.10. Weight percentage before chemical and after each chemical etching step.

The obtained EDX weight percent of silver and paste of samples before and after successive etching processes is shown in Fig. 10. Ag weight decreased dramatically after AR treatment. This change shows that, although the glass seems to cover up to the tips of the pyramids (Fig. 7), the AR treatment was effective on the glass and was able to remove part of the silver in it. After first $\mathrm{Ag}$ etching the main element detected was $\mathrm{Si}$ with a $64 \%$. This weight increased after the subsequent treatments reaching $94 \%$ after AR, HF, AR processing.

After AR, HF treatments some paste residues in the samples were found, however, they were mainly composed by silver. Thus, the etching process successfully removed most of the glass. Signals from silver crystallites, which were underneath the glass, were then obtained. An increase in the $\mathrm{Ag}$ weight percent was observed. This result demonstrates that the small agglomerates or, clusters observed in Fig. 8, were indeed silver crystallites and very little glass remained in the sample.

After AR, HF, AR etching all silver was removed and small glass residues remained in the sample (Fig. 9). The final glass weight was $0.7 \%$. Apart from glass and $\mathrm{Si}$, a $\mathrm{C}$ signal was detected. Carbon is a permanent contaminant in EDX measurements, therefore it was not considered as part of the paste.

The main elements which compose the paste (except silver), oxygen and lead, are shown in Fig. 10 (center). Part of the O signal detected in the EDX measurements corresponded to oxygen associated with silicon. From the silicon bare surface, it was observed that it corresponds to $1 \%$, approximately. This $1 \%$ was subtracted to calculate the total glass weight and from the oxygen bars presented in Fig. 10 (center). Elements detected in low concentrations, also constituents of the paste are $\mathrm{Al}$ and $\mathrm{K}$ (Fig. 10 right). Not only paste weight percent changed after different treatments but also its composition (Fig. 10 center). The paste in the sample before treatment seems to be only composed by $\mathrm{O}, \mathrm{Pb}$ and $\mathrm{Al} . \mathrm{PbO}$ is an important component of the paste since it reduces the viscosity and melting point of the glass ${ }^{31,32,33}$. Al presence is in accordance with the use of $\mathrm{Al}_{2} \mathrm{O}_{3}$ for advanced silver pastes ${ }^{34,35}$.

After first $\mathrm{Ag}$ removal, $\mathrm{PbO}$ is the main component of the glass. This compound was observed as an increase in $\mathrm{Pb}$ and $\mathrm{O}$ weight percent (Fig. 10 center) were measured. With much less presence of $\mathrm{Ag}$ in the sample, potassium in the glass was detected. $\mathrm{K}$ is one of the alkali elements which have been incorporated into modern silver pastes. After this AR treatment, $1.3 \%$ of 
nitrogen was detected. This element probably came from the SiNx layer, which was not completely etched and it was observed after Ag removal.

After the $\mathrm{AR}$ and $\mathrm{HF}$ treatments, $2 \%$ of $\mathrm{Cl}$ was detected. This might have come from the $\mathrm{AR}$ bath, which contains $\mathrm{HCl}$, although it is interesting to notice that it appeared only after the HF step, which removed the paste. This result may be explained by the decrease of glass components, which (apart from silver) were almost completely removed from the sample. Thus, at this stage the glass weight percent, excluding silver, was only $8 \%$, still mainly composed by $\mathrm{PbO}$.

After AR, HF, AR treatments not only all the silver was removed but also all the lead in the glass. Only elements left behind, apart from $\mathrm{Si}$, are $\mathrm{O}, \mathrm{Al}$ and $\mathrm{K}$. At this stage $\mathrm{K}$ weight percent was higher than that of aluminum. $\mathrm{Pb}$ and part of Al may have been removed with AR since they were counted among the metals capable of tolerating AR corrosive properties.

\section{CONCLUSIONS}

In this work, the goal was to present an approach to experimentally investigate the contacting interface of the screen printed metallized front contact using thick film silver pastes for industrial solar cells. The approach consisted of the application of a sequence of chemical solutions to selectively remove the components of the contact. For analysis, scanning electron microscopy (SEM) and energy dispersive X-ray spectrometry (EDX) were used. The complete experiment and evaluation led to the following conclusions.

The front side contact of a p-type silicon solar cell is composed by the silver finger, an inhomogeneous glass layer and silver crystallites grown into n-type silicon. After application of the sequence of chemical solutions, the three main components were selectively removed. layer behind.

Agua regia effectively removed the silver finger leaving the glass

- Weight percentage of silver reduced $95 \%$ to $3 \%$ after first aqua regia etching step.

- $\quad$ Agua regia also removed aluminum of the rear side contact.

- Hydrofluoric acid completely removed the glass layer leaving silver which was, according to the model and microscopy investigation, behind the glass. They consisted on silver agglomerates but not necessary silver crystallites.

- Accordingly, the weight percentage of silver after hydrofluoric acid increased from $3 \%$ to $16 \%$.

- A subsequent second aqua regia application removed any possible grown silver crystallites revealing the contact points (contact imprints). The contact imprints were found at the pyramid tips and edges close to the tips.

- Weight percentage of silver reduced from $16 \%$ to $0.04 \%$ after second aqua regia etching.

- Consequently, silver crystallites preferably grew on pyramid tips and edges of the n-type silicon.

- A small fraction of the utilized silver in the paste produced silver crystallites after the firing step and was enough to lead to a high efficiency (19\%) and a high fill factor (78\%).

The selective chemical etching can be applied for further experiments to study solar cells which are metallized with silver pastes having differences in the physical properties and chemical composition. Each screen printed and fired silver paste must be studied and optimized with respect to all preceding processing steps of the whole fabrication.

The methodology can be further improved in order to reduce the amount of residuals after the application of the chemical solutions. In concrete, concentration of the reactants and times can be reduced to produce the same result.

\section{APPENDIX}

\section{A. THE SILICON SOLAR CELL}

A solar cell is a semiconductor device consisting of a p-n junction and metalized regions that directly converts sunlight into electricity where a portion of the electromagnetic radiation is absorbed in the semiconductor (such as silicon). If the energy of an incoming photon ( $E_{u}=h v=h c / \lambda$ being $h$ Planck's constant, the $v$ frequency, $\lambda$ the wavelength and $c$ the speed of light) is larger than the bandgap $\left(E_{g}\right)$ of the semiconductor, then an electron is released from the valence band in the silicon lattice to the conduction band leaving a hole. Thus, an electron-hole pair is created. These charge carriers can be separated due to an electric field, locally formed in the p-n junction. After electron-hole pairs are created and separated, these must be collected and conducted through metal contacts out from the semiconductor to an external circuit.

A.1. Solar cell processing

A typical industrial solar cell process based on p-type material can be described as follows. First, the (100) oriented surfaces of the p-type wafers are improved by removing the damage from sawing and by giving an adequate shape to reduce light reflexion. This step is called texturization where wafers are treated in an alkaline solution of $\mathrm{NaOH}$ and Isopropyl Alcohol (IPA) (or KOH/IPA). Pyramids of $7 \mu \mathrm{m}$ size with (111) planes are created due to the anisotropical etching of silicon. After that, wafers are immersed in $\mathrm{HCl}$ to eliminate metal impurities and in HF to remove oxide. Then, phosphorus diffusion in a quartz tube furnace is carried out to create a p-n junction. The commonly used precursor is $\mathrm{POCl}_{3}$. A further cleaning step in HF removes the formed phosphorus silicate glass (PSG) layer produced during diffusion. Next, a silicon nitride layer $(\mathrm{SiNx}){ }^{5}$ is deposited by Plasma Enhanced Chemical Vapor Deposition (PECVD) acting as an anti reflexion and passivation layer on n-type silicon. Metal contacts are screen printed by using metal pastes (see section 2.2 and 2.3). A co-firing step follows to finish the contacts (see section $2.4)$, and finally a laser edge isolation step completes the process ${ }^{4}$.

\section{ACKNOWLEDGMENTS}

The authors acknowledge the generous financial support provided by the Education Ministry of Chile Grant PMI ANT 1201 as well as CONICYT/ FONDAP/ 15110019 "Solar Energy Research Center" SERC-Chile and the BMBF Solar Collaboration between Chile and Deutschland (Solar Child) project number 01DN14005

\section{REFERENCES}

1. Fraunhofer-Institut für Solare Energiesysteme ISE, Photovoltaics Report: July 2014.

2. International Technology Roadmap for Photovoltaic (ITRPV), 2014.

3. M.M. Hilali, K. Nakayashiki, C. Khadilkar, R.C. Reedy, A. Rohatgi, A. Shaikh, S. Kim, S. Sridharan, J. Electrochem. Soc. 153, 1, A5-A11, (2006).

4. D. H. Neuhaus, A. Muenzer, Advances in OptoElectronics, 2007, 24521, (2007).

5. A. El amrani, I. Menous, L. Mahiou, R. Tadjine, A. Touati, A. Lefgoum, Renewable Energy 33, 2289-2293, (2008).

6. L. Sardi, S. Bargioni, C. Canali, P. Davoli, M. Prudenziati, V. Valbusa, Solar Cells, 11, 1, (1984).

7. D. K. Anderson, R.D. Anderson, K. W. Hang, S.M.Kao, G. Laudisio, C.N Lin, C.K Wu, Patent Application No ${ }^{\circ}$ US 8372679 B2, (2013).

8. Restriction of Hazardous Substances (RoHS) or electrical and electronic equipment: http://ec.europa.eu/environment/waste/rohs_eee/index_ en.htm, accessed on 16/10/14.

9. N. Merchant, Y. Yang, C. McKinley, H. Kerp, P. van Eijk, A. Shaikh, E. Gradd, Proc. 24th EU PVSEC, Hamburg, Germany, (2009).

10. B. Sopori, V. Mehta, P. Rupnowski, J. Appel, M. Romero, H. Moutinho, D. Domine, B. To, R. Reedy, M. Al-Jassim, A. Shaikh, N. Merchant, C. Khadilkar, D. Carlson, M. Bennet, , 17th Workshop on Crystalline Silicon Solar Cells \& Modules: Materials and Processes, Colorado USA, (2007).

11. D. Pysch, A. Mette, A. Filipovic, S. Glunz, Prog. Photovoltaics Res. App. 17, 101-114, (2009).

12. M. Rauer, C. Schmiga, J. Krause, R.Woehl, M. Hermle, S. W. Glunz,Energy Procedia 8, 200-206, (2011).

13. P. Ferrada, "Diffusion through Oxide Barriers for Solar Cell Applications", Ph.D. Thesis, University of Konstanz, (2012).

14. E. Cabrera, "Screen Printed Ag Contacting Interface in Industrial Crystalline Silicon Solar Cells", Ph.D. Thesis, University of Konstanz, (2013).

15. M. M. Hilali, "Understanding and Development of Manufacturable Screen printed Contacts on High-Sheet Resistance Emitters for Low-Cost Silicon Solar Cells", PhD Thesis, Georgia Institute of Technology, (2005).

16. G. Schubert, "Thick film metallisation of crystalline silicon solar cells", Ph.D. Thesis, University of Konstanz, Konstanz, Germany (2006).

17. C. Ballif, D.M. Huljic, G. Willeke, A. Hessler-Wyser, App. Phys. Lett. 82, $12,1878-1880,(2003)$.

18. S. Kontermann, "Characterization and modeling of contacting crystalline silicon solar cells", Ph.D. Thesis. University of Konstanz, Konstanz, Germany (2009).

19. M. M. Hilali, M. M. Al-Jassim, B. To, H. Moutinho, A. Rohatgi, S. Asher, J. Electrochem. Soc. 152, 10, G742-G749, (2005).

20. M. Hoerteis, "Fine-line printed contacts on crystalline silicon solar cells", Ph.D. Thesis. University of Konstanz, Konstanz, Germany (2009).

21. Z. Li, L. Liang, L. Cheng, J. App. Phys. 105, 066102, (2009).

22. E. Sugimura, S. Takamoto, S. Tsujii, K. Hirata, A. Tani and T. Fuyuki, J. 
Appl. Phys. 51, 10NA02, (2012).

23. J. Haunschild, M. Glatthaar, M. Kasemann, S. Rein and E. R. Weber, Phys. Status Solidi RRL, 3, 227-229, (2009).

24. S. Kontermann, M. Hoerteis, A. Ruf, S. Feo and R. Preu, Phys. Status Solidi (a), 206, 2866-2871, (2009).

25. R. A. Sinton, A. Cuevas, Appl. Phys. Lett. 69, 17, 2510-2512, (1996).

26. A. F. Hollemann, E. Wiberg, N. Wiberg, Lehrbuch der Anorganischen Chemie, $33^{\text {rd }}$ ed., Walter de Gruyter, Berlin, 1985.

27. M. Green, Solid-State Electron, 24,788-789, (1981).

28. E. Cabrera, S. Olibet, D. Rudolph, E. Wefringhaus, R. Kopecek, D. Reinke, G. Schubert, IEEE J. Photovoltaics, 3 (1), (2012).

29. M.M. Hilali, K. Nakayashiki, C. Khadilkar, R.C. Reedy, A. Rohatgi, A. Shaikh, S. Kim, S. Sridharan, J. Electrochem. Soc. 153 (1), A5-A11, (2006).

30. M.M. Hilali, A. Rohatgi, C. Khadilkar, S. Kim, T. Pham, J. Salami, A.
Shaikh, S. Sridharan, "Understanding and development of Ag pastes for silicon solar cells with high-sheet resistance emitters", Proc. $19^{\text {th }}$ EU PVSEC, Paris, France, (2004).

31. Brekhovskikh S. M, Glass and Ceramics 14 (8), 264-267 (1957). DOI: 10.1007/BF00672836.

32. K.J. Rao, "Structural Chemistry of Glasses", Elsevier Science, 1st Edition, Oxford (2002). ISBN: 978-0-08-043958-7.

33. H. Krebs, Angewandte Chemie 78 (11), $577-587$ (1966). DOI: 10.1002/ ange. 19660781104.

34. G. Schubert, "Untersuchung der Dickfilmmetallisierung für kristalline Silizium-Solarzellen", M. Sc. Thesis, University of Konstanz, Konstanz, Germany (2002).

35. G. Laudisio, R. J. S. Young, P. J. Willmot, K. W. Hang, "Metal pastes and use thereof in the production of silicon solar cells", Patent Application Publication, US 0240124 A1 (2011). 